\title{
An Analysis of the Effects of Blood Pressure and Antihypertensive Drugs on Heart Disease
}

\author{
Kazumitsu Nawata1,2, Hayato Sugano', Moriyo Kimura ${ }^{3}$ \\ ${ }^{1}$ Graduate School of Engineering, University of Tokyo, Tokyo, Japan \\ ${ }^{2}$ Research Institute of Economy, Trade and Industry (RIETI), Tokyo, Japan \\ ${ }^{3}$ The Public Health Institute, Tokyo, Japan \\ Email: nawata@tmi.t.u-tokyo.ac.jp, haya.0919.455@gmail.com, kimuramoriyo@gmail.com
}

How to cite this paper: Nawata, K., Sugano, H. and Kimura, M. (2019) An Analysis of the Effects of Blood Pressure and Antihypertensive Drugs on Heart Disease. Health, 11, 792-816.

https://doi.org/10.4236/health.2019.116064

Received: May 26, 2019

Accepted: June 22, 2019

Published: June 25, 2019

Copyright $\odot 2019$ by author(s) and Scientific Research Publishing Inc. This work is licensed under the Creative Commons Attribution International License (CC BY 4.0).

http://creativecommons.org/licenses/by/4.0/

\begin{abstract}
Background: The American College of Cardiology (ACC), American Heart Association (AHA) and other organizations announced a new hypertension guideline (2017 ACA/AHA Guideline) in November 2017. However, other organizations such as the European Society of Cardiology and European Society of Hypertension maintained their diagnostic thresholds. It is necessary to evaluate the effects of blood pressure (BP) and antihypertensive drugs on the probability of having heart disease (HD). Data and Methods: The effects of BP, antihypertensive drugs and other factors on the probability of undergoing HD treatment were analyzed. We used a dataset containing 83,287 medical check-up and treatment records obtained from 35,504 individuals in 5 fiscal years. The probit models were used in the study. Considering the possibility of endogeneity problems, different types of models were used. Results: We could not find evidence that a higher systolic BP increased the probability of undergoing HD treatment. However, diastolic BP increased the probability in most of the models. Taking antihypertensive drugs also increased the probability of undergoing HD treatment. Diabetes was another important risk factor. Conclusion: The results of this study did not support the new 2017 ACC/AHA Guideline. It is necessary to choose proper drugs and methods to reduce the risks of side effects. Limitations: The dataset was observatory, the data were obtained from just one medical society, and sample selection bias might exist.
\end{abstract}

\section{Keywords}

Heart Disease, 2017 ACC/AHA Hypertension Guideline,

Hypertension, Blood Pressure, Antihypertensive Drug,

Diabetes 


\section{Introduction}

High blood pressure (BP) or hypertension is considered one of the most important health risk factors. The World Health Organization (WHO) [1] mentioned that "Worldwide, raised blood pressure is estimated to cause 7.5 million deaths, about $12.8 \%$ of the total of all deaths. This accounts for 57 million disability adjusted life years (DALYS) or $3.7 \%$ of total DALYS. Raised blood pressure is a major risk factor for coronary heart disease and ischemic as well as hemorrhagic stroke". WHO and the International Society of Hypertension (ISH) [2] estimated that hypertension is estimated to cause $4.5 \%$ of the current global disease burden. Gaziano et al. [3] also estimated that the global cost of suboptimal BP was $\$ 370$ billion ( $\$$ refers to US $\$$ ) in 2001 . More recently, the cost of hypertension in the United States became $\$ 51.2$ billion per year in 2012-2013 [4] [5]. The Centers for Disease Control and Prevention [6] also estimated that the cost of hypertension was $\$ 48.6$ billion. In Japan, the medical expenditure on hypertension was 1.8 trillion yen in fiscal year 2016 [7], and it is considered a very important disease. Furthermore, it has been reported that hypertension reduces quality of life [8] [9] and it has been suggested that the real cost of hypertension including indirect costs might be higher.

The distribution of BP is continuous, and several criteria of hypertension were proposed. For example, the Japanese Society of Hypertension (JSH) [10] and the Blood Pressure Association of United Kingdom [11] diagnosed hypertension if the systolic BP (SBP) was $140 \mathrm{mmHg}$ or more or the diastolic BP (DBP) was 90 mmHg or over (hereafter, 140/90). The National Heart, Lung and Blood Institute of the United States [12] classified hypertension into Stage 1 (SBP of 140 $159 \mathrm{mmHg}$; DBP of $90-99 \mathrm{mmHg}$ ) and Stage 2 (SBP of $160 \mathrm{mmHg}$ or over; DBP of $100 \mathrm{mmHg}$ or over). WHO and ISH [13] classified hypertension into the following three categories: Grade 1 (mild), SBP of $140-159 \mathrm{mmHg}$ or DBP of 90 - $99 \mathrm{mmHg}$; Grade 2 (moderate), SBP of 160 - $179 \mathrm{mmHg}$ or DBP of 100 $109 \mathrm{mmHg}$; and Grade 3 (severe), SBP of $180 \mathrm{mmHg}$ or over or DBP of 110 $\mathrm{mmHg}$ or over. They predicted the probability of serious cardiovascular disease (CVD) in the next 10 years based on BP and other risk factors. The probabilities were $20 \%-30 \%$ and $30 \%$ or more in the high- and very-high-risk groups, respectively.

In November, 2017, the American College of Cardiology (ACC), American Heart Association (AHA), and nine other organizations presented the "2017 ACC/AHA/AAPA/ABC/ACPM/AGS/APhA/ASH/ASPC/NMA/PCNA Guideline for the Prevention, Detection, Evaluation, and Management of High Blood Pressure in Adults" [14] (hereafter the 2017 ACC/AHA Guideline). In the 2017 ACC/AHA Guideline, the criterion for hypertension is $130 / 80 \mathrm{mmHg}$. Furthermore, the 2017 ACC/AHA Guideline changed "prehypertension" to "elevated BP" (SBP of $120-129 \mathrm{mmHg}$, DBP below $80 \mathrm{~mm} \mathrm{Hg}$ ) and defined "Stage 1 hypertension" as SBP of $130-139 \mathrm{mmHg}$ or DBP of $80-89 \mathrm{mmHg}$, and "Stage 2 hypertension" as SBP of $140 \mathrm{mmHg}$ or over or DBP of $90 \mathrm{mmHg}$ or over and replaced 
the previous 160/100 $\mathrm{mmHg}$ criterion [15] [16]. They also declared that numerous innovations and modifications to the guidelines were implemented beginning in 2017 [17]. This is the first major revision since the "Seventh report of the joint national committee on prevention, detection, evaluation, and treatment of high blood pressure (JNC 7)" in 2003 [16] [18] [19]. The 2017ACC/AHA Guideline is an official policy of the ACC/AHA, and it targets treatments in the United States; however, it will likely have an effect throughout the world, as noted in the guideline itself [14].

Khera et al. [20] estimated that $63 \%$ and $55 \%$ of the populations in the 45 -to 75-year-old age groups would be considered to have hypertension in the Unites States and China with the adoption of the 2017 ACC/AAHA Guideline, respectively. Chung et al. [21] reported that the national weighted prevalence rates of brachial hypertension according to the 2017 guideline would be $40.7 \%$ in men and $30.7 \%$ in women, increasing by $18.8 \%$ and $9.4 \%$ in men and women, respectively, from that determined according to the previous criterion in Taiwan. Marchesan and Spritzer [22] reported that the prevalence of systemic arterial hypertension among women with polycystic ovary syndrome was $65 \%$ according to the 2017 ACC/AHA Guideline and 26.6\% according to the JNC7 criterion.

On the other hand, the European Society of Cardiology and the European Society of Hypertension (ESC/ESH) [23], Hypertension Canada [24] [25] and the American Diabetes Association [26] maintained the diagnostic threshold of $140 / 90 \mathrm{mmHg}$ for the general public in their 2018 guidelines. The Japanese Society of Hypertension (JSH) has been revising the 2014 Guidelines for the Management of Hypertension (JSH 2014 Guideline), and in their 2019 guideline declared that "We will not change the definition or category of hypertension because we think it appropriate to define hypertension as the level of BP at which the benefits of treatment unequivocally outweigh risks of treatment in the line of ESC/ESH guidelines" [27]. Moreover, the American Academy of Family Physicians (AAFP) [28], an organization that initially adopted the 2017 ACC/AHA Guideline, declared that they would not follow the 2017 ACC/AHA Guideline and would use the previous guideline. The AAFP explained that systematic reviews of the new guideline had not been done, that the prevalence of hypertension among US adults would increase from $32 \%$ to $46 \%$, and that substantial weight had been given to the Systolic Blood Pressure Intervention Trial (SPRINT) [29] but that other trials were minimized.

The present paper aims to analyze the effects of $\mathrm{BP}$ and antihypertensive drugs on heart disease (HD). We used the data from 83,287 medical checkups and treatment records obtained from 35,504 individuals in 5 fiscal years, 2011, $2012,2014,2015$, and 2016. The data were obtained with the cooperation of one health insurance society. The results of the medical checkups were combined with the receipts, monthly medical reports sent from medical institutes to the health insurance societies, and the probabilities of undergoing HD treatment were analyzed using probit analysis. 


\section{Reviews of Previous Studies}

Many studies of the relationships between BP and health conditions have been done, including the well-known, long-term Framingham Heart Study (FHS) [30], which has been continuously conducted by Boston University and the National Heart, Lung, \& Blood Institute since 1948 in Framingham, Massachusetts. As the initial cohort, 5209 males and females aged 30 - 62 without clear signs or symptoms of HD were chosen. The study has found that male sex, age, cholesterol, SBP and diabetes are prediction factors of CVD over the course of 30 years.

The SPRINT [29], weighted heavily in the 2017ACC/AHA Guideline, was a trial in which 9361 persons with SBP of $130 \mathrm{mmHg}$ or higher and an increased CVD risk, but without diabetes, were randomly assigned into two groups. One group was the intensive treatment group of 4678 persons with an SBP target less than $120 \mathrm{mmHg}$ and the other was the standard treatment group of 4683 persons. The enrollment period ran from November 2010 to March 2013, and the trial was terminated earlier than the planned period. The median follow-up period on August 20, 2015 was 3.26 years, and the planned average period was 5 years. The trial found lower rates of fatal and nonfatal major cardiovascular events and of death from any cause. In the trial, lifestyle modifications were encouraged. The average numbers of BP medications given to participants were 2.8 and 1.8, and the mean SBP values were 121.5 and $134.6 \mathrm{mmHg}$ in the intensive treatment and standard treatment groups, respectively. However, the SPRINT was not a blinded, randomized clinical trial. The participants and doctors (or researchers) could easily know which groups the participants belonged to. Therefore, we could not deny effects similar to the placebo effect [31] [32]. The rates of death from any cause were similar for the first two years, and the number of participants decreased after 3 years or more. Lowering BP with medications may cause adverse effects. The SPRINT research group themselves admitted that [29] "acute kidney injury, ... were higher in the intensive-treatment group than in the standard-treatment group". With regard to SPRINT, also see Leung et al. [33].

SPRINT used the same method used by the Action to Cardiovascular Risk in Diabetes (ACCORD) Study Group [34]. The ACCORD study involved 4733 persons with type 2 diabetes. The ACCORD study reported that lowering the SBP below $120 \mathrm{mmHg}$ did not reduce the major CVD or death rates compared to the cases in which the SBP was lowered below $140 \mathrm{mmHg}$.

The Prospective Studies Collaboration [35] performed a meta-analysis using individual data for one million adults obtained from the results of 61 prospective studies. In this study, they analyzed 12.7 million person-years and reported 56,000 vascular mortalities including 12,000 due to stroke and 34,000 due to ischemic HD (IHD). They also reported that deaths due to IHD increased as SBP and DBP increased in all age cohorts (from 40 - 49 to 80 - 89).

Ettehad et al. [36] performed a meta-analysis using 123 studies selected from 11,428 studies that focused on lowering BP from January 1966 and July 2015. 
The total number of individuals included in the analysis was 613,815 . They reported that treatments for lowering BP significantly reduced the major CVD risk and that lowering SBP by $10 \mathrm{mmHg}$ reduced mortality rates from all causes by $13 \%$.

Joffres et al. [37] analyzed BP using Canadian (Canadian Heart Health Survey (CHHS)) and US (NHANESIII) data. These data included 23,111 observations in Canada and 15,326 in the United States. They reported similar trends concerning age in both datasets, with prevalence rates of diabetes in the age range of $10-74$ of $20.1 \%$ in the NHANES and $21.1 \%$ in the CHHS, and about half of diabetes patients had hypertension and were managed poorly.

Rapsomaniki et al. [38] did an analysis of 2.25 million people from 1977 to 2010 using CALIBAR (CArdiovascular research using LInked Bespoke studies and Electronic health Records). In the analysis, CVD was observed for the first time in 83,098 cases. They concluded that the lifetime risks of CVD for hypertensive individuals at age 30 would be $63.3 \%$ compared to $46.1 \%$ for normotensive individuals and that hypertensive individuals would exhibit CVD 5 years earlier than normotensive individuals.

Muntner et al. [39] used data from the 2011-2012 and 2013-2014 cycles of the National Health and Nutrition Examination Survey (NHANES) and analyzed 10,907 adult patients. They declared that the 2017 ACC/AHA Guideline would increase the use of hypertension drugs and lower the prevalence of CVD events. However, in their analysis, while some characteristics of the patients were considered, "obesity" was not. Ihum et al. [40] discussed the issues, particularly the optimal target BP, from an Asian perspective.

In Japan, a survey of "Nippon Data 2010" [41] performed using funds from the Ministry of Health, Labor and Welfare was done. In this survey, the BP levels of 2891 participants were recorded and the average SBP levels were 137.4 for males and $130.8 \mathrm{mmHg}$ for females. In a national survey, SBP has been declining for 50 years for all ages and genders. However, for DBP, the same trend was observed for females but not males [42]. Fujiyoshi et al. [43] analyzed the relation between BP and CVD using a dataset of 63,309 individuals by cohorts based on age and gender. They reported 1944 CVD mortalities in 10.2 years and a positive relation between CVD and BP. Asayama et al. [44] analyzed the mortality risk due to CVD of 39,705 participants (the median follow-up period was 10.0 years) of 6 cohorts that satisfied necessary conditions from among 13 cohorts that were part of EPOCH-JAPAN. They reported that in individuals without treatment, the risk of CVD mortality became higher even if the effects of age, body mass index (BMI), anamnesis of CVD, diabetes, total cholesterol, smoking, and belonging cohorts were considered in the Cox proportional hazard model. However, a clear relation between the hypertension stages and CVD mortality risk was not observed for males undergoing hypertension treatment.

The Department of Epidemiology and Public Health, in the Graduate School of Medical Sciences at Kyushu University, has been doing a long-lasting epide- 
miological survey (Kugayama Study) for residents of the town of Kugayama (population about 8400) in Fukuoka Prefecture since 1961, for over 50 years [45]. Honda et al. [46] analyzed 2462 residents aged 40 - 84 for 24 years using the Cox proportional hazard model. They reported age, gender, SBP, hemoglobin A1c (HbA1c) low-density lipoprotein cholesterol (LDL), high-density lipoprotein cholesterol (HDL), smoking, and daily exercise as prediction factors of CVD.

Most studies mentioned that a higher SBP made the risk of CVD higher. However, questions have arisen about the results of previous studies, as pointed out by Nawata, Sekizawa, and Kimura [47]. Biases such as publication, conflict of interest, and termination (or endpoint) biases might exist in these studies. The selection criteria of the studies might also be problematic for meta-analysis. Although the selection criteria should have been determined before the studies were done, they were in fact determined after the studies ended, which might cause another type of bias. For the cohort studies, the effects of individual characteristics other than $\mathrm{BP}$ could not be removed if the cohort interval was too large. For example, 10-year (or longer) age cohort intervals were often used. Nawata et al. [48] found that SBP increased by about $5 \mathrm{mmHg}$ with 10 years of increased age, and thus the 10-year age cohort interval might have been too large. Sample-selection biases and the selection of explanatory variables were other important problems to be properly treated [49].

More recently, Nawata and Kimura [49] [50] analyzed the total annual medical expenditures and results of BP measured using the power transformation Tobit models for a dataset containing 175,123 cases obtained from 88,211 individuals. They found that the medical expenditure declined as SBP increased. Although their target was the medical expenditure which represented the overall health conditions and not only CVD, the results were the opposite of those of most studies. Nawata and Kimura [50] also analyzed if individuals had CVD/HD as anamnesis by the probit model. They found a negative relationship between SBP and having CVD/HD in the anamnesis. The problem of the study is that they considered anamnesis obtained from inquiries done at medical checkups, which means that the individuals might not have had CVD/HD at the time of the medical checkups and that the information might not be correct because the information relied on the memories of individuals.

\section{Data and Methods}

\subsection{Data}

Japan has a public health insurance system that requires all citizens to belong to some type of public health insurance organization. Most employees 40 years of age or older are required to undergo medical checkups once a year by law [51], and family members can also undergo medical checkups on a voluntary basis. The dataset was created with the cooperation of a health insurance society formed by a group of small corporations. All employees of the corporations and their family members are required to belong the health insurance society. The 
monthly reports of all medical treatments and payments sent from medical institutes to the health insurance societies are called "receipts". We used a dataset containing 83,287 observations obtained from 35,504 individuals for which both the results of medical checkups and receipts were available in the same fiscal year. (The Japanese fiscal year starts in April and ends in March of the next year.) The sample period was from April 2011 to December 2014 and from April 2015 to February 2017. Unfortunately, we could not obtain the data for fiscal year 2013. Receipts were classified into five categories: dental; inpatients of DPC hospitals; outpatients and inpatients of non-DPC hospitals; and pharmacies. Of these, we used the sum of DPC, outpatient \& non-DPC hospital, and pharmacy receipts as the medical expenditures. The medical expenditures are measured by points in Japan. Ten yen per points are paid to medical institutes. Figure 1 shows the distribution of medical expenditures. The distribution is skewed and has a very heavy tail on the right side. A total of $32.4 \%$ of all observations of medical expenditures are zero. On the other hand, $1.0 \%, 0.3 \%$, and $0.1 \%$ used more than 100,000, 250,000 and 500,000 points, and their medical expenditures accounted for $26.3 \%, 13.7 \%$ and $6.0 \%$ of total medical expenditures.

Under the 140/90 criterion, 20.7\% were diagnosed with hypertension. Under the 2017 ACC/AHA Guideline of 130/80, this value jumps up to $49.0 \%$, about a half of observations, suggesting the effect of changing the criterion is quite large. The definitions of CVD/HD were not very clear and might not have been the same as in previous studies. To avoid ambiguity in the definitions, the diseases classified as HD were chosen according to the classification of the Ministry of Health, Labour and Welfare [52], which is based on the International Disease Classification 10th Revision (ICD 10) of WHO [53]. HD selected in this paper included: acute rheumatic fever, chronic rheumatic $\mathrm{HD}$, hypertensive $\mathrm{HD}$, ischemic $\mathrm{HD}$, pulmonary HD, diseases of pulmonary circulation, and other forms of HD. Among 83,287 observations, 5942, or 7.1\%, were for individuals undergoing HD treatments.

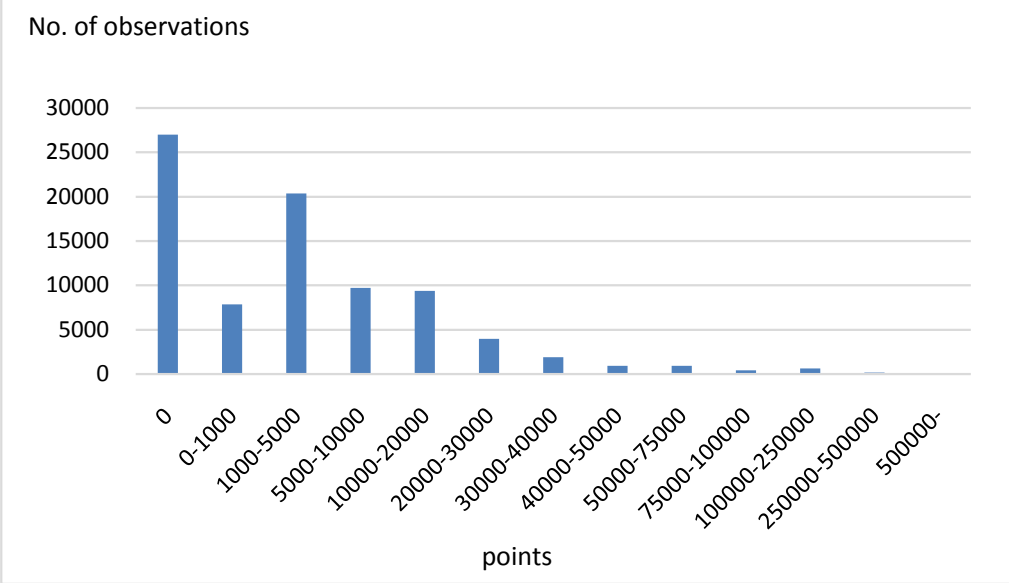

Figure 1. Distribution of medical expenditures. 


\subsection{Probit Model}

In many studies, including SPRINT, the Cox proportional hazard method [54] is used. However, Cox's method is improper when time-dependent or time-varying covariates are included, as shown in Appendix A. Therefore, we used the probit model. Let $H D_{i t}$ be a dummy variable taking 1 if an individual was undergoing HD treatment in fiscal year $t$ and 0 otherwise. The basic model is given by

$$
\begin{gathered}
Y_{i t}^{*}=x_{i t}^{\prime} \beta+u_{i t} \\
H D_{i t}=1 \text { if } Y_{i t}^{*}>0 \text { and } \\
H D_{i t}=0 \text { if } Y_{i t}^{*} \leq 0 \text {, and } \\
\mathrm{P}\left(H D_{i t}=1\right)=\mathrm{P}\left(Y_{i t}^{*}>0\right)=\Phi\left(x_{i t}^{\prime} \beta\right)
\end{gathered}
$$

where $\mathrm{P}\left(H D_{i t}=1\right)$ is the probability that $H D_{i t}=1, x_{i t}$ is a vector of covariates, $u_{i t}$ follows the standard normal distribution, and $\Phi$ is the distribution function of the standard normal distribution. $Y_{i t}^{*}$ is a latent variable, and only its sign is observable.

\section{Models and Covariates}

\subsection{Covariates Used in the Analysis}

\begin{tabular}{|c|c|}
\hline Variable & Variable \\
\hline Age & $\begin{array}{l}\text { Eat_fast ( } 0 \text { : eating faster than other people; } \\
1 \text { : normal; } 2 \text { : slower })\end{array}$ \\
\hline Female (1: if female; 0 : otherwise) & $\begin{array}{l}\text { Late_supper (1: eating supper within two hours before } \\
\text { bedtime three times or more in a week; 0: otherwise) }\end{array}$ \\
\hline Height $(\mathrm{cm})$ & $\begin{array}{l}\text { After_supper (1: eating snacks after supper three times } \\
\text { or more in a week, } 0 \text { : otherwise) }\end{array}$ \\
\hline $\begin{array}{l}\text { BMI }(\text { Body Mass Index })= \\
\text { weight }(\mathrm{Kg}) / \text { height }(\mathrm{m})^{2}\end{array}$ & $\begin{array}{l}\text { No_breakfast (1: not eating breakfast three times or } \\
\text { more in a week; } 0 \text { : otherwise) }\end{array}$ \\
\hline $\mathrm{SBP}(\mathrm{mmHg})$ & $\begin{array}{l}\text { Exercise (1: doing exercise for } 30 \text { minutes or more twice } \\
\text { or more in a week for more than a year; } 0 \text { : otherwise) }\end{array}$ \\
\hline DBP (mmHg) & $\begin{array}{l}\text { Daily_activity (1: doing physical activities (walking or } \\
\text { equivalent) for one hour or more daily, } 0 \text { : otherwise), }\end{array}$ \\
\hline $\begin{array}{l}\text { HDL (high-density lipoprotein } \\
\text { cholesterol, mg/dL) }\end{array}$ & $\begin{array}{l}\text { Speed (1: walking faster than other people of a similar age } \\
\text { and the same gender; } 0 \text { : otherwise) }\end{array}$ \\
\hline $\begin{array}{l}\text { LDL (low-density lipoprotein } \\
\text { cholesterol, mg/dL) }\end{array}$ & Smoke (1: smoking; 0 : otherwise) \\
\hline Triglyceride (mg/dL) & $\begin{array}{l}\text { Alcohol_freq ( } 0 \text { : not drinking alcoholic drinks, } \\
\text { 1: sometimes, } 2 \text { : everyday) }\end{array}$ \\
\hline
\end{tabular}

We considered several different models, and the covariates used in this study were as follows (Table 1):

Table 1. Covariates used in the estimation. 


\section{Continued}

\begin{tabular}{|c|c|}
\hline $\begin{array}{l}\text { GGP ( } \gamma \text {-glutamyl transferase, } \\
\text { units per liter: U/L) }\end{array}$ & $\begin{array}{l}\text { Alcohol_amount (0: not drinking; } 1 \text { : drinking less than } \\
180 \mathrm{ml} \text { of Japanese sake wine (with an alcohol percentage } \\
\text { of about } 15 \% \text { ) or equivalent alcohol in a day when } \\
\text { drinking; 2: drinking } 180 \text { - } 360 \mathrm{ml} \text {; 3: drinking } 360 \text { - } 540 \\
\text { ml; 4: drinking } 540 \mathrm{ml} \text { or more) }\end{array}$ \\
\hline AST (aspartate aminotransferase, U/L) & $\begin{array}{l}\text { Sleep (1: sleeping well; } 0 \text { : otherwise), Diabetes (getting } \\
\text { diabetes treatments; } 0 \text { : otherwise) }\end{array}$ \\
\hline ALT (alanine aminotransferase, U/L) & Diabetes (getting diabetes treatments; 0: otherwise) \\
\hline Blood_sugar (mg/dL) & $\begin{array}{l}\text { Antihypertensive (1: taking antihypertensive drugs, } 0 \text { : } \\
\text { otherwise) }\end{array}$ \\
\hline $\begin{array}{l}\text { Urine_sugar (integers of } 1-5 \text {, sugar in } \\
\text { urine increasing with number; } 1 \text { is } \\
\text { normal, } 5 \text { is worst) }\end{array}$ & F_year11 (1: fiscal year 2011; 0: otherwise) \\
\hline Urine_protein (same as Urine_sugar) & F_year12 (1: fiscal year 2012; 0: otherwise) \\
\hline HbAlc (hemoglobin Alc, \%) & F_year14 (1: fiscal year 2014; 0: otherwise) \\
\hline $\begin{array}{l}\text { Weight_20 (weight increased by } 10 \mathrm{~kg} \text { or } \\
\text { more from age } 20 \text { ) }\end{array}$ & F_year15 (1: fiscal year 15; 0: otherwise) \\
\hline
\end{tabular}

Age, Female and Height represent basic individual characteristics; BMI represents obesity; while HDL, LDL, and Triglyceride represent the lipid concentration in the blood [55]. If the lipid concentration is abnormal, an individual is diagnosed with dyslipidemia, and dyslipidemia is currently mainly hyperlipidemia, in which the lipid concentration is too high. Although our bodies need lipids to build cells, an excess of lipids could be a problem [56]. LDL and HDL cholesterol levels are classified as "bad" and "good" [57] [58]. GGP, AST and ALT are mainly related to liver functions; Blood_sugar, HbA1c and Urine_sugar are important indicators of diabetes; and Urine_protein represents the condition of the kidneys [59]. The Antihypertensive covariate evaluates the effects of antihypertensive drugs.

\subsection{Estimated Models}

We first estimated the relation between undergoing HD treatment and the values of the covariates in the same fiscal year. Since taking antihypertensive drugs obviously affects the values of SBP and DBP, we considered two models given by:

Model A:

$$
\begin{aligned}
Y_{i t}^{*}= & \beta_{1}+\beta_{2} \mathrm{Age}+\beta_{3} \text { Female }+\beta_{4} \mathrm{Height}+\beta_{5} \mathrm{BMI}+\beta_{6} \mathrm{SBP} \\
& +\beta_{7} \mathrm{DBP}+\beta_{8} \mathrm{HDL}+\beta_{9} \mathrm{LDL}+\beta_{10} \text { Triglyceride }+\beta_{11} \mathrm{GGP} \\
& +\beta_{12} \mathrm{AST}+\beta_{13} \mathrm{ALT}+\beta_{14} \mathrm{Blood} \_ \text {sugar }+\beta_{15} \mathrm{HbAl} \mathrm{c} \\
& +\beta_{16} \text { Urine_sugar }+\beta_{17} \text { Urine_protein }+\beta_{18} \text { Weight } \_20 \\
& +\beta_{19} \text { Weight_ } 1+\beta_{20} \text { Eat_fast }+\beta_{21} \text { Late_supper }
\end{aligned}
$$


$+\beta_{22}$ After_supper $+\beta_{23}$ No_breakfast $+\beta_{24}$ Exercise

$+\beta_{25}$ Daily_activity $+\beta_{26}$ Walk_fast $+\beta_{27}$ Smoke

$+\beta_{28}$ Alcohol_freq $+\beta_{29}$ Alcohol_amount $+\beta_{30}$ Sleep

$+\beta_{31}$ Diabetes $+\beta_{32} \mathrm{~F} \_$year $11+\beta_{33} \mathrm{~F} \_$year 12

$+\beta_{34} \mathrm{~F} \_$year $14+\beta_{35} \mathrm{~F} \_$year $15+u_{1 i t}$

Model B:

$$
\begin{aligned}
& Y_{i t}^{*}=\beta_{1}+\beta_{2} \text { Age }+\beta_{3} \text { Female }+\beta_{4} \text { Height }+\beta_{5} \mathrm{BMI}+\beta_{6} \mathrm{SBP} \\
& +\beta_{7} \mathrm{DBP}+\beta_{8} \mathrm{HDL}+\beta_{9} \mathrm{LDL}+\beta_{10} \text { Triglyceride }+\beta_{11} \mathrm{GGP} \\
& +\beta_{12} \mathrm{AST}+\beta_{13} \mathrm{ALT}+\beta_{14} \mathrm{Blood} \_ \text {sugar }+\beta_{15} \mathrm{HbAlc} \\
& +\beta_{16} \text { Urine_sugar }+\beta_{17} \text { Urine_protein }+\beta_{18} \text { Weight_20 } \\
& +\beta_{19} \text { Weight_ } 1+\beta_{20} \text { Eat_fast }+\beta_{21} \text { Late_supper } \\
& +\beta_{22} \text { After_supper }+\beta_{23} \text { No_breakfast }+\beta_{24} \text { Exercise } \\
& +\beta_{25} \text { Daily_activity }+\beta_{26} \text { Walk_fast }+\beta_{27} \text { Smoke } \\
& +\beta_{28} \text { Alcohol_freq }+\beta_{29} \text { Alcohol_amount }+\beta_{30} \text { Sleep } \\
& +\beta_{31} \text { Diabetes }+\beta_{32} \mathrm{~F} \_ \text {year } 11+\beta_{33} \mathrm{~F} \_ \text {year } 12 \\
& +\beta_{34} \mathrm{~F} \_ \text {year14 }+\beta_{35} \mathrm{~F} \_ \text {year15 }+\beta_{36} \text { Antihypertensive }+u_{2 i t}
\end{aligned}
$$

\begin{tabular}{|c|c|c|c|c|}
\hline Variable & Average & SD & Variable & \\
\hline Age & 50.2 & 9.0 & Weight_20 & $1: 40.7 \% ; 0: 59.3 \%$ \\
\hline Female & \multicolumn{2}{|c|}{$1: 32.5 \% ; 0: 67.5 \%$} & Weight_1 & $1: 29.8 \% ; 0: 70.2 \%$ \\
\hline Height & 165.1 & 8.5 & Exercise & $\begin{array}{l}0: 30.0 \% ; 1: 60.9 \% \\
2: 9.1 \%\end{array}$ \\
\hline BMI & 23.1 & 3.8 & Daily_activity & 1:41.6\%; 0:58.4\% \\
\hline SBP & 123.6 & 18.2 & Speed & $1: 13.5 \% ; 0: 86.5 \%$ \\
\hline DBP & 76.2 & 12.5 & Eat_fast & $1: 29.2 \% ; 0: 70.8 \%$ \\
\hline HDL & 61.6 & 16.7 & Late_supper & $1: 24.8 \% ; 0: 75.2 \%$ \\
\hline $\mathrm{LDL}$ & 125.0 & 33.0 & After_supper & $1: 38.6 \% ; 0: 61.4 \%$ \\
\hline Triglyceride & 123.7 & 107.7 & No_breakfast & $1: 43.3 \%, 0: 56.7 \%$ \\
\hline GTP & 44.6 & 56.1 & Smoke & $1: 41.8 \%, 0: 58.2 \%$ \\
\hline ATL & 24.8 & 20.3 & Drink_freq & $\begin{array}{l}0: 26.2 \% ; 1: 35.9 \% \\
2: 37.9 \%\end{array}$ \\
\hline AST & 23.9 & 23.1 & Drink_amount & $\begin{array}{l}0: 37.9 \% ; 1: 19.6 \% \\
2: 24.9 \% ; 3: 13.1 \% ; \\
4: 4.5 \%\end{array}$ \\
\hline Blood_sugar & 81.7 & 40.6 & Sleep & $1: 56.5 \% ; 0: 43.5 \%$ \\
\hline $\mathrm{HbA} 1 \mathrm{c}$ & 1.889 & 2.374 & Diabetes & $1: 13.2 \% ; 0: 86.8 \%$ \\
\hline
\end{tabular}

Model A does not include Antihypertensive, and Model B includes Antihypertensive. Excluding observations with missing covariate values, we used 73,471 observations $\left(H D_{i t}=1: 5301\right.$, and $\left.H D_{i t}=0: 68,710\right)$ for the estimation of the model. A summary of the covariates is given in Table 2. Hereafter we refer to Model A and Model B as HD models.

Table 2. Summary of covariates. 


\section{Continued}

\begin{tabular}{|c|c|c|c|}
\hline Urine_sugar & $\begin{array}{l}\text { 1:96.1\%; } 2: 0.6 \% ; 3: 1.0 \% \\
4: 0.8 \% ; 5: 1.4 \%\end{array}$ & Antihypertension & $1: 14.2 \% ; 0: 85.8 \%$ \\
\hline Urine_protein & $\begin{array}{l}\text { 1:91.8\%; } 2: 4.5 \% ; 3: 2.6 \% \\
\text { 4:0.8\%; 5: } 0.3 \%\end{array}$ & Fiscal year & $\begin{array}{l}11: 18.9 \%, 12: 26.5 \% \text {; } \\
\text { 14: } 18.7 \% ; 15: 21.3 \% \text {; } \\
16: 14.5 \%\end{array}$ \\
\hline
\end{tabular}

SD: Standard Deviation.

Antihypertensive drugs might be used for the HD treatment. In such cases, Antihypertensive might be an endogenous variable, and we cannot use the standard method for estimation of the model. Hence, we considered the following models for those who did not undergo HD treatment at time $t$ and for whom we could get information regarding the HD treatment at time $t+1$.

Model C:

$$
\begin{aligned}
& Y_{i t+1}^{*}=\beta_{1}+\beta_{2} \text { Age }+\beta_{3} \text { Female }+\beta_{4} \text { Height }+\beta_{5} \mathrm{BMI}+\beta_{6} \mathrm{SBP} \\
& +\beta_{7} \mathrm{DBP}+\beta_{8} \mathrm{HDL}+\beta_{9} \mathrm{LDL}+\beta_{10} \text { Triglyceride }+\beta_{11} \mathrm{GGP} \\
& +\beta_{12} \mathrm{AST}+\beta_{13} \mathrm{ALT}+\beta_{14} \mathrm{Blood} \_ \text {sugar }+\beta_{15} \mathrm{HbAlc} \\
& +\beta_{16} \text { Urine_sugar }+\beta_{17} \text { Urine } \_ \text {protein }+\beta_{18} \text { Weight } \_20 \\
& +\beta_{19} \text { Weight } \_1+\beta_{20} \text { Eat_fast }+\beta_{21} \text { Late_supper } \\
& +\beta_{22} \text { After_supper }+\beta_{23} \text { No_breakfast }+\beta_{24} \text { Exercise } \\
& +\beta_{25} \text { Daily_activity }+\beta_{26} \text { Walk_fast }+\beta_{27} \text { Smoke } \\
& +\beta_{28} \text { Alcohol_freq }+\beta_{29} \text { Alcohol_amount }+\beta_{30} \text { Sleep } \\
& +\beta_{31} \text { Diabetes }+\beta_{32} \mathrm{~F} \_ \text {year } 11+\beta_{33} \mathrm{~F} \_ \text {year } 12 \\
& +\beta_{34} \mathrm{~F} \_ \text {year } 14+\beta_{35} \mathrm{~F} \_ \text {year } 15+u_{3 i t+1}
\end{aligned}
$$

Model D:

$$
\begin{aligned}
& Y_{i t+1}^{*}=\beta_{1}+\beta_{2} \text { Age }+\beta_{3} \text { Female }+\beta_{4} \text { Height }+\beta_{5} \mathrm{BMI}+\beta_{6} \mathrm{SBP} \\
& +\beta_{7} \mathrm{DBP}+\beta_{8} \mathrm{HDL}+\beta_{9} \mathrm{LDL}+\beta_{10} \text { Triglyceride }+\beta_{11} \mathrm{GGP} \\
& +\beta_{12} \mathrm{AST}+\beta_{13} \mathrm{ALT}+\beta_{14} \mathrm{Blood} \_ \text {sugar }+\beta_{15} \mathrm{HbAlc} \\
& +\beta_{16} \text { Urine_sugar }+\beta_{17} \text { Urine_protein }+\beta_{18} \text { Weight } \_20 \\
& +\beta_{19} \text { Weight } \_1+\beta_{20} \text { Eat_fast }+\beta_{21} \text { Late_supper } \\
& +\beta_{22} \text { After_supper }+\beta_{23} \text { No_breakfast }+\beta_{24} \text { Exercise } \\
& +\beta_{25} \text { Daily_activity }+\beta_{26} \text { Walk_fast }+\beta_{27} \text { Smoke } \\
& +\beta_{28} \text { Alcohol_freq }+\beta_{29} \text { Alcohol_amount }+\beta_{30} \text { Sleep } \\
& +\beta_{31} \text { Diabetes }+\beta_{32} \mathrm{~F} \_ \text {year1 } 1+\beta_{33} \mathrm{~F} \_ \text {year } 12 \\
& +\beta_{34} \mathrm{~F} \_ \text {year } 14+\beta_{35} \mathrm{~F} \_ \text {year } 15+\beta_{36} \text { Antihypertensive }+u_{4 i t+1}
\end{aligned}
$$

$Y_{i t+1}^{*}$ is a variable observed at $t+1$. On the other hand, the covariates on the right-hand side are measured at the previous fiscal $t$. (To avoid unnecessary complications, we eliminated the subscript $t$ for covariates on the right-hand side of the equations. Since the data for fiscal year 2013 were not available, the 2014 and 2012 data are used for $t+1$ and $t$ when $t=2012$.) Since individuals did not undergo HD treatment in fiscal year $t$, we can void the endogeneity problem. Hereafter we refer to Model $\mathrm{C}$ and Model $\mathrm{D}$ as the predicting HD models. A total of 36,416 observations satisfied $H D_{t i}=0$, and the values of $H D_{t+1 i}$ could be 
observed; 34,947 were $\left(H D_{t i}=0, H D_{t+1 i}=0\right)$ and 1469 were $\left(H D_{t i}=0\right.$, $\left.H D_{t+1 i}=1\right)$.

\subsection{Results of Estimation}

Table 3 shows the estimation results of Model A and Model B. A positive estimate value means that the variable increases the probability of undergoing $\mathrm{HD}$ treatment. In these models, undergoing HD treatment and the covariates were measured in the same fiscal year, and the values of the covariates might have been affected by the HD treatment. The estimates of variables other than Antihypertensive were similar in both models. For BP variables, the estimates of SBP were negative in both models and significant at the $1 \%$ level in Model B. The estimates of DBP were positive and significant at the $1 \%$ level in both models. This means that the probability of undergoing HD treatment became significantly higher as DBP becomes higher, but this is not true for SBP. Antihypertensive was positive and significant at the $1 \%$ level in Model B. For non-BP variables, the estimates of Age, BMI, DBP, Weight_1, Urine_protein, Weight_1 and Diabetes and the fiscal year dummies were positive and significant at the $1 \%$ level in both models. The estimates of Female were positive and significant at least at the 5\% level in both models. The estimates of AST and Drink_amount were positive in both models and significant at the 5\% level in one model. The estimates of LDL, Speed, Smoke, and Drink_freq were negative and significant at the $1 \%$ level in both models. The estimates of HDL, ATL and Urine_sugar were negative and significant (at least) at the $5 \%$ level in both models. The estimates of No_breakfast were negative in both and significant at the 5\% level in Model B. The estimates of other covariates were not significant in Model A and Model B.

The results of Model C and Model D are given in Table 4. In these models, undergoing $\mathrm{HD}$ treatment was measured at $t+1$ (i.e., $H D_{i t+1}$ ), and all covariates were measured at (the previous year) $t$. Moreover, we selected individuals who were not undergoing $\mathrm{HD}$ treatment at $t\left(\right.$ i.e., $\left.H D_{i t}=0\right)$. Therefore, all covariates were free from the endogeneity problem. Since the number of observations became smaller (total: $36,416, H D_{t+1 i}=0: 34,947$ and $H D_{t+1 i}=1: 1469$ ), the absolute $\mathrm{t}$-values tended to be smaller than those in the previous models. The estimates of SBP and DBP were positive in both models, and the estimate of DBP was significant at the $5 \%$ level in Model D. The estimate of Antihypertensive was positive and significant at the $1 \%$ level in Model D. For non-BP covariates, the estimates of Age, Female, Blood_sugar, Weight_1, Diabetes, and all fiscal year dummies were positive and significant at the $1 \%$ level. The estimates of AST were positive and significant at the $5 \%$ level, and the estimates of Daily_activity were negative and significant at the $5 \%$ level in both models. The estimates of No_breakfast were negative and significant at the 5\% level in one model. These variables were considered to be important predictors of undergoing HD treatment in the next fiscal year. All other covariates were not significant in Model C or Model D. 
Table 3. Results of estimation (Model A and Model D).

\begin{tabular}{|c|c|c|c|c|c|c|c|}
\hline & Model $A$ & & & & Model I & & \\
\hline Variable & Estimate & SE & $\mathrm{t}$-value & Variable & Estimate & SE & $\mathrm{t}$-value \\
\hline Constant & -3.7596 & 0.2743 & $-13.70^{* *}$ & Constant & -3.3273 & 0.2793 & $-11.91^{* *}$ \\
\hline Age & 0.0269 & 0.0010 & $27.35^{* *}$ & Age & 0.0193 & 0.0010 & $18.77^{* *}$ \\
\hline Female & 0.0579 & 0.0268 & $2.164^{*}$ & Female & 0.0725 & 0.0272 & $2.668^{* *}$ \\
\hline Height & 0.0012 & 0.0014 & 0.902 & Height & 0.0023 & 0.0014 & 1.647 \\
\hline BMI & 0.0210 & 0.0026 & $8.027^{* *}$ & BMI & 0.0089 & 0.0027 & $3.289^{* *}$ \\
\hline SBP & -0.0012 & 0.0007 & -1.633 & SBP & -0.0024 & 0.0007 & $-3.365^{* *}$ \\
\hline DBP & 0.0041 & 0.0010 & $3.975^{* *}$ & DBP & 0.0042 & 0.0011 & $4.006^{* *}$ \\
\hline HDL & -0.0019 & 0.0006 & $-3.211^{* *}$ & $\mathrm{HDL}$ & -0.0014 & 0.0006 & $-2.330^{*}$ \\
\hline LDL & -0.0030 & 0.0003 & $-11.99^{* *}$ & LDL & -0.0021 & 0.0003 & $-8.183^{* *}$ \\
\hline Triglyceride & 0.00004 & 0.0001 & 0.462 & Triglyceride & 0.00004 & 0.0001 & 0.395 \\
\hline GTP & 0.00004 & 0.0002 & -0.276 & GTP & -0.0001 & 0.0002 & -0.577 \\
\hline ATL & -0.0012 & 0.0006 & $-2.025^{*}$ & ATL & -0.0017 & 0.0006 & $-2.846^{* *}$ \\
\hline AST & 0.0006 & 0.0004 & 1.780 & AST & 0.0009 & 0.0004 & $2.379^{*}$ \\
\hline Blood_sugar & 0.0003 & 0.0002 & 1.383 & Blood_sugar & 0.0002 & 0.0002 & 1.153 \\
\hline $\mathrm{HbAlc}$ & -0.0039 & 0.0067 & -0.580 & $\mathrm{HbAlc}$ & -0.0083 & 0.0068 & -1.230 \\
\hline Urine_sugar & -0.0386 & 0.0120 & $-3.211^{* *}$ & Urine_sugar & -0.0273 & 0.0122 & $-2.236^{*}$ \\
\hline Urine_protein & 0.0881 & 0.0130 & $6.793^{* *}$ & Urine_protein & 0.0608 & 0.0133 & $4.591^{* *}$ \\
\hline Weight_20 & -0.0195 & 0.0190 & -1.025 & Weight_20 & -0.0288 & 0.0193 & -1.489 \\
\hline Weight_1 & 0.0929 & 0.0175 & $5.301^{* *}$ & Weight_1 & 0.0913 & 0.0178 & $5.122^{* *}$ \\
\hline Exercise & -0.0235 & 0.0194 & -1.213 & Exercise & -0.0170 & 0.0197 & -0.864 \\
\hline Daily_activity & 0.0053 & 0.0173 & 0.303 & Daily_activity & 0.0060 & 0.0176 & 0.342 \\
\hline Speed & -0.0815 & 0.0163 & $-4.992^{* *}$ & Speed & -0.0735 & 0.0166 & $-4.426^{* *}$ \\
\hline Eat_fast & -0.0054 & 0.0135 & -0.398 & Eat_fast & -0.0039 & 0.0137 & -0.283 \\
\hline Late_supper & -0.0077 & 0.0172 & -0.448 & Late_supper & -0.0121 & 0.0175 & -0.696 \\
\hline After_supper & -0.0102 & 0.0236 & -0.431 & After_supper & 0.0116 & 0.0239 & 0.484 \\
\hline No_breakfast & -0.0496 & 0.0192 & $-2.592^{* *}$ & No_breakfast & -0.0334 & 0.0195 & -1.710 \\
\hline Smoke & -0.0891 & 0.0176 & $-5.070^{* *}$ & Smoke & -0.0756 & 0.0179 & $-4.226^{* *}$ \\
\hline Drink_freq & -0.0510 & 0.0152 & $-3.363^{* *}$ & Drink_freq & -0.0792 & 0.0155 & $-5.094^{* *}$ \\
\hline Drink_amount & 0.0236 & 0.0106 & $2.235^{*}$ & Drink_amount & 0.0185 & 0.0108 & 1.710 \\
\hline Sleep & -0.0447 & 0.0159 & $-2.805^{* *}$ & Sleep & -0.0514 & 0.0162 & $-3.168^{* *}$ \\
\hline Diabetes & 0.9750 & 0.0178 & $54.66^{* *}$ & Diabetes & 0.8473 & 0.0185 & $45.74^{* *}$ \\
\hline F_year11 & 0.2528 & 0.0424 & $5.958^{* *}$ & F_year11 & 0.2713 & 0.0433 & $6.263^{* *}$ \\
\hline F_year12 & 0.2526 & 0.0396 & $6.376^{* *}$ & F_year12 & 0.2775 & 0.0404 & $6.870^{* *}$ \\
\hline F_year14 & 0.4881 & 0.0287 & $17.03^{* *}$ & F_year14 & 0.5075 & 0.0293 & $17.33^{* *}$ \\
\hline \multirow[t]{2}{*}{ F_year15 } & 0.4165 & 0.0281 & $14.82^{* *}$ & F_year15 & 0.4362 & 0.0287 & $15.18^{* *}$ \\
\hline & & & & Antihypertensive & 0.6274 & 0.0195 & $32.10^{* *}$ \\
\hline $\log \mathrm{L}$ & \multicolumn{3}{|c|}{$-15,796.72$} & $\log \mathrm{L}$ & \multicolumn{3}{|c|}{$-15,288.8$} \\
\hline
\end{tabular}

SE: standard error, ${ }^{*}$ : significant at the $5 \%$ level, ${ }^{* *}$ : significant at the $1 \%$ level. 73,471 observations $\left(H D_{i t}=1: 5301\right.$, and $\left.H D_{i t}=0: 68,710\right)$. 
Table 4. Results of estimation (Model C and Model D).

\begin{tabular}{|c|c|c|c|c|c|c|c|}
\hline & & Model C & & & & Model D & \\
\hline Variable & Estimate & S.E. & $\mathrm{t}$-value & Variable & Estimate & SE & $\mathrm{t}$-value \\
\hline Constant & -4.4543 & 0.4477 & $-9.949^{* *}$ & Constant & -4.3784 & 0.4470 & $-9.796^{* *}$ \\
\hline Age & 0.0206 & 0.0017 & $12.46^{* *}$ & Age & 0.0182 & 0.0017 & $10.77^{* *}$ \\
\hline Female & 0.1733 & 0.0440 & $3.938^{* *}$ & Female & 0.1876 & 0.0438 & $4.283^{* *}$ \\
\hline Height & 0.0026 & 0.0022 & 1.166 & Height & 0.0030 & 0.0022 & 1.359 \\
\hline BMI & 0.0078 & 0.0045 & 1.727 & BMI & 0.0057 & 0.0045 & 1.270 \\
\hline SBP & 0.0005 & 0.0012 & 0.410 & SBP & 0.00004 & 0.0012 & 0.037 \\
\hline DBP & 0.0032 & 0.0017 & 1.854 & DBP & 0.0037 & 0.0017 & $2.144^{*}$ \\
\hline HDL & -0.0014 & 0.0010 & -1.435 & HDL & -0.0013 & 0.0010 & -1.338 \\
\hline LDL & 0.0000 & 0.0004 & -0.120 & LDL & 0.0002 & 0.0004 & 0.447 \\
\hline Triglyceride & 0.0001 & 0.0001 & 0.727 & Triglyceride & 0.0001 & 0.0001 & 0.688 \\
\hline GTP & -0.0002 & 0.0003 & -0.681 & GTP & -0.0002 & 0.0003 & -0.692 \\
\hline ATL & 0.0000 & 0.0011 & 0.012 & ATL & -0.0002 & 0.0011 & -0.165 \\
\hline AST & 0.0026 & 0.0013 & $2.096^{*}$ & AST & 0.0027 & 0.0013 & $2.183^{*}$ \\
\hline Blood_sugar & 0.0009 & 0.0003 & $2.979^{* *}$ & Blood_sugar & 0.0010 & 0.0003 & $3.060^{* *}$ \\
\hline $\mathrm{HbAlc}$ & 0.0039 & 0.0099 & 0.399 & $\mathrm{HbAlc}$ & 0.0036 & 0.0099 & 0.363 \\
\hline Urine_sugar & 0.0185 & 0.0216 & 0.858 & Urine_sugar & 0.0166 & 0.0215 & 0.773 \\
\hline Urine_protein & 0.0303 & 0.0242 & 1.254 & Urine_protein & 0.0138 & 0.0241 & 0.575 \\
\hline Weight 20 & 0.0126 & 0.0310 & 0.406 & Weight_20 & 0.0063 & 0.0310 & 0.203 \\
\hline Weight_1 & 0.0775 & 0.0286 & $2.712^{* *}$ & Weight $=1$ & 0.0779 & 0.0285 & $2.735^{* *}$ \\
\hline Exercise & 0.0164 & 0.0316 & 0.519 & Exercise & 0.0181 & 0.0316 & 0.574 \\
\hline Daily_activity & -0.0588 & 0.0286 & $-2.058^{*}$ & Daily_activity & -0.0567 & 0.0285 & $-1.992^{*}$ \\
\hline Speed & -0.0209 & 0.0263 & -0.793 & Speed & -0.0186 & 0.0262 & -0.709 \\
\hline Eat_fast & -0.0247 & 0.0220 & -1.122 & Eat_fast & -0.0245 & 0.0219 & -1.116 \\
\hline Late_supper & 0.0426 & 0.0276 & 1.547 & Late_supper & 0.0410 & 0.0275 & 1.490 \\
\hline After_supper & -0.0224 & 0.0381 & -0.588 & After_supper & -0.0226 & 0.0380 & -0.596 \\
\hline No_breakfast & -0.0592 & 0.0301 & $-1.963^{*}$ & No_breakfast & -0.0559 & 0.0301 & -1.858 \\
\hline Smoke & -0.0100 & 0.0282 & -0.354 & Smoke & 0.0008 & 0.0282 & 0.027 \\
\hline Drink_freq & -0.0139 & 0.0241 & -0.576 & Drink_freq & -0.0214 & 0.0241 & -0.886 \\
\hline Drink_amount & 0.0179 & 0.0167 & 1.070 & Drink_amount & 0.0152 & 0.0167 & 0.908 \\
\hline Sleep & -0.0412 & 0.0258 & -1.599 & Sleep & -0.0494 & 0.0257 & -1.924 \\
\hline Diabetes & 0.3065 & 0.0366 & $8.381^{* *}$ & Diabetes & 0.2568 & 0.0375 & $6.838^{* *}$ \\
\hline F_year11 & 0.4120 & 0.0662 & $6.226^{* *}$ & F_year11 & 0.4196 & 0.0663 & $6.332^{* *}$ \\
\hline F_year12 & 0.8546 & 0.0637 & $13.42^{* *}$ & F_year12 & 0.8644 & 0.0638 & $13.56^{* *}$ \\
\hline \multirow[t]{2}{*}{ F_year14 } & 0.6670 & 0.0479 & $13.94^{* *}$ & F_year14 & 0.6776 & 0.0480 & $14.13^{* *}$ \\
\hline & & & & Antihypertensive & 0.2170 & 0.0369 & $5.884^{* *}$ \\
\hline $\log \mathrm{L}$ & \multicolumn{3}{|c|}{-5709.861} & $\log \mathrm{L}$ & \multicolumn{3}{|c|}{-5693.143} \\
\hline
\end{tabular}

SE: standard error, ${ }^{*}$ : significant at the $5 \%$ level, ${ }^{* *}$ : significant at the $1 \%$ level. 36,416 observations $\left(H D_{t+1 i}=0: 34,947\right.$ and $\left.H D_{t+1 i}=1: 1469\right)$. 


\section{Discussion}

First, we considered the effects of SBP and DBP on HD. In all four models, the estimates of SDP were either negative or insignificant. On the other hand, all estimates of DBP were positive and significant at least at the 5\% level in three models. Although previous studies such as the SPRINT and ACCORD trials mainly considered SBP to represent hypertension, the results of this paper suggest that DBP is a more important factor to be considered. To clarify the meaning of these results, we replaced SBP and DBP with BP_level $=(\mathrm{SBP}+\mathrm{DBP}) / 2$ and BP_difference $=$ SBP - DBP in Models A-D. We denoted these as Models A'-D'; BP_level represents the absolute level of BP, and BP_difference is the difference between SBP and DBP, which is important in sending blood through the body. The results of the estimation of BP_level and BP_difference are given in Table 5. Since BP_level and BP_difference were obtained by linear transformations of SBP and DBP, the results of all of the other covariates were unchanged. The estimates of BP_level were positive and significant at the $1 \%$ level in all models. The estimates of BP_difference were negative in all models and significant at the $1 \%$ level in Models A' and B'. In Model B', the absolute value of the estimate of BP_difference was almost twice as large as that of BP_level. These results strongly suggest that both $\mathrm{SBP}$ and $\mathrm{DBP}$ should be considered in the evaluation of BP. Lowing SBP is not sufficient, and lowering DBP is more important. Nawata, Sekizawa, and Kimura [47] suggested that taking antihypertensive drugs would reduce SBP by $9.17 \mathrm{mmHg}$. Using the same model, taking antihypertensive drugs would reduce DBP by $6.14 \mathrm{mmHg}$. (The results of the estimation are given in Table 6 in Appendix B). This means that the BP level decreased by $7.65 \mathrm{mmHg}$ (not 9.17) and the difference between SBP and DBP decreased by $3.0 \mathrm{mmHg}$. In other words, the effect of antihypertensive drugs might be smaller than previously considered.

The estimates of Antihypertensive were 0.627 and 0.217 with t-values of 32.10 and 5.88 in Model B and Model D, respectively. The values of the estimates and $\mathrm{t}$-values were much larger than those of the other covariates except Diabetes. This means that taking antihypertensive drugs would increase the probability of undergoing HD treatment. As mentioned earlier, the endogeneity problem, namely that antihypertensive drugs might be used for the HD treatment, might exist in Model B, but we obtained the same results in Model D. The following three possible hypotheses can be considered:

1) The health conditions of individuals taking antihypertensive drugs were worse than those not taking antihypertensive drugs, and they were in the pre-stages of HD.

2) Individuals taking antihypertensive drugs went to hospitals or clinics more frequently than those not taking antihypertensive drugs. As a result, HD was more likely to be found earlier.

3) The antihypertensive drugs have rather negative side effects on HD which outweigh the benefits of the drugs. 
Table 5. Result of estimation of BP_level and BP_difference.

\begin{tabular}{ccccccc}
\hline Model & \multicolumn{3}{c}{ BP_level } & \multicolumn{3}{c}{ BP_difference } \\
\hline & Estimates & SE & t-value & Estimates & SE & t-value \\
\hline $\mathrm{A}^{\prime}$ & 0.0030 & 0.0007 & $4.436^{* *}$ & -0.0026 & 0.0008 & $-3.212^{* *}$ \\
$\mathrm{~B}^{\prime}$ & 0.0018 & 0.0007 & $2.643^{* *}$ & -0.0033 & 0.0008 & $-3.976^{* *}$ \\
$\mathrm{C}^{\prime}$ & 0.0037 & 0.0011 & $3.427^{* *}$ & -0.0014 & 0.0014 & -0.985 \\
$\mathrm{D}^{\prime}$ & 0.0035 & 0.0011 & $3.254^{* *}$ & -0.0016 & 0.0014 & -1.137 \\
\hline
\end{tabular}

SE: standard error, ${ }^{* *}$ : significant at the $1 \%$ level.

Table 6. Effect of antihypertensive drugs on DBP.

\begin{tabular}{|c|c|c|c|}
\hline Variable & Estimate & SE & $\mathrm{t}$-value \\
\hline Constant & 90.0361 & 6.1016 & $14.756^{* *}$ \\
\hline Age & -0.2053 & 0.0292 & $-7.025^{* *}$ \\
\hline Female & -0.4223 & 0.7331 & -0.576 \\
\hline Height & 0.0076 & 0.0318 & 0.238 \\
\hline BMI & 0.4113 & 0.0482 & $8.538^{* *}$ \\
\hline Anamnesis & -2.1793 & 0.3890 & -5.603 \\
\hline Weight_1 & -0.6381 & 0.3933 & -1.623 \\
\hline Eat_fast & -0.0252 & 0.3899 & -0.065 \\
\hline Late_supper & -0.3466 & 0.3759 & -0.922 \\
\hline After_supper & -0.9152 & 0.5685 & -1.610 \\
\hline No_breakfast & 1.3835 & 0.4373 & $3.164^{* *}$ \\
\hline Exercise & -1.2154 & 0.4888 & $-2.487^{*}$ \\
\hline Daily_activity & -0.7951 & 0.4302 & -1.848 \\
\hline Speed & 0.2750 & 0.3800 & 0.724 \\
\hline Smoke & -0.7154 & 0.3763 & -1.901 \\
\hline Drink_freq & 0.9043 & 0.3233 & $2.797^{* *}$ \\
\hline Drink_amount & 0.2328 & 0.2275 & 1.023 \\
\hline Sleep & 0.2927 & 0.3784 & 0.774 \\
\hline Trend & -0.3246 & 0.2409 & -1.348 \\
\hline Antihypertensive & -6.1390 & 0.4063 & $-15.109^{* *}$ \\
\hline $\mathrm{R}^{2}$ & & 0.1347 & \\
\hline No. of observations & & 4315 & \\
\hline
\end{tabular}

SE: standard error, ${ }^{* *}$ : significant at the $1 \%$ level, ${ }^{*}$ : significant at the $5 \%$ level.

Various factors affecting the participants' health conditions were considered in our models. If the first hypothesis is correct, we missed some important factors that might affect HD, and it is necessary to identify such factors and add them to medical checkups. We cannot evaluate the second and third hypotheses 
precisely at the current stage and cannot reject the third hypothesis.

The major pharmacological classes of antihypertensive drugs used are [60] [61] [62]: calcium channel blockers, angiotensin II receptor antagonists, angiotensin-converting enzyme inhibitors, diuretics, and $\beta$-blockers. In addition to these medicines, alpha-adrenergic receptor blockers and others (including vasodilators, centrally acting drugs, and renin inhibitors) are used based on the conditions of the patients. Every drug has side effects [63]. For the mechanism of action of the side effects, see the review work of Laurent [62]. It is necessary to choose the proper methods [64] and drugs to reduce the risks of side effects [61] [65]. These results suggested that the 2017 ACC/AHA Guideline was not supported. We could not deny the possibility that the negative side effects might be more significant than the benefits of the antihypertensive drugs. We need more detailed analyses using a larger dataset with a longer time-range to assess the benefits and negative side effects.

Most of the estimates of the other covariates had the expected signs. Although LDL cholesterol is referred to as "bad" cholesterol, higher LDL values lowered the probability of undergoing HD treatment. Also, although the reason is unknown, higher levels of urine sugar also reduced the probability of undergoing HD treatment. Smoking lowered the probability of undergoing HD treatment; however, other negative effects of smoking were not analyzed in this paper. Age, gender, weight change of more than $3 \mathrm{~kg}$ within a year, and diabetes were significant in both the having and predicting HD models. Among these covariates, the estimates and t-values of Diabetes were very large in all models. Special care is necessary to prevent HD in individuals with these risk factors, especially those with diabetes. BMI, ALT, AST, walking faster than other people, not eating breakfast, and sleeping well were significant factors in the HD models. The estimation results of the predicting models suggested that AST and blood sugar levels might be important predicting factors, and that daily physical activities might reduce the probability of undergoing HD treatment in the next year. All fiscal year dummies were positive and significant in all models. This may reflect the fact that the number of months included in fiscal year 2016 was smaller than that in the other fiscal years.

\section{Conclusion}

In this study, the effects of BP and antihypertensive drugs on the probabilities of undergoing HD treatment were analyzed using the probit model. The data of 83,287 medical checkups involving 35,504 individuals were combined with medical records of HD treatments in fiscal years 2011, 2012, 2014, 2015 and 2016. The data were obtained with the cooperation of one health insurance society. We first evaluated the probabilities of undergoing HD treatment in the same fiscal years using the two HD models. The estimates of SBP were negative in both HD models and significant in one model. On the other hand, estimates of DBP were positive in the HD models. The HD treatment might affect the values 
of the covariates, and an endogeneity problem might exist. To avoid this problem, we next evaluated individuals who were not undergoing HD treatment in fiscal year $t$ and the probabilities that these individuals would undergo HD treatment in the next fiscal year, $t+1$, with the two predicting HD models. The estimates of SBP become positive, but they were not significant. The estimates of DBP were positive and significant in one model. These results might imply that DBP was a more important risk factor than SBP. Levels of BP should be defined using both SBP and DBP (such as by using the average), and differences in SBP and DBP should also be considered. Therefore, previous studies that just focused on SBP, such as ACCORD and SPRINT, should be revised. We then evaluated the effects of hypertensive drugs. Surprisingly, taking hypertensive drugs made the probability of undergoing HD treatment higher. It is necessary to choose proper drugs and methods to reduce the risks of side effects, considering the various health conditions of individuals. These results did not support the 2017 ACC/AHA Guideline.

Most of the estimates of other covariates have the expected signs. However, the estimates of LDL, referred to as "bad" cholesterol, were negative and significant as those of HDL ("good" cholesterol). The estimates of Urine_sugar and Smoke were also negative in the HD models. However, other negative effects of smoking were not analyzed in this paper. Age, Female, AST, Weight_1, and Diabetes were significant in both the HD and predicting HD models. In particular, diabetes was considered a very important risk factor. BMI, ALT, No_breakfast Drink_amount, Drink_freq, and Sleep were significant in the HD models. The estimates of Blood_sugar were positive in the predicting HD models.

Although the guidelines of the ESC/ESH, Hypertension Canada, American Diabetes Association, and JSH maintained the diagnostic threshold of 140/90 $\mathrm{mmHg}$ for the general public, the influence of the 2017 ACC/AHA Guideline is so large that further studies to reevaluate the relationships among BP, antihypertensive drugs, and various health conditions should be done as soon as possible. This study is based on the dataset from just one health insurance society, and a sample selection bias might exist. Analyses using a larger dataset with a longer time-range from various insurance societies are necessary. We are now negotiating various health insurance societies to provide us their data. There are several types of antihypertensive drugs. It is also necessary to determine their effects and the side effects of the drugs more precisely. These are topics to be studied in the future.

\section{Acknowledgements}

This study was supported by a Grant-in-Aid for Scientific Research, "Analyses of Medical Checkup Data and Possibility of Controlling Medical Expenses (Grant Number: 17H22509)", from the Japan Society of Science, and by a research grant, "Exploring Inhibition of Medical Expenditure Expansion and Health-oriented Business Management Based on Evidence-based Medicine" from the Research 
Institute of Economics, Trade and Industry (RIETI). The dataset was anonymized at the health insurance society. This study was approved by the Institutional Review Boards of the University of Tokyo (number: KE17-30). The authors would like to thank the health insurance society for their sincere cooperation in providing us the data. We would also like to thank an anonymous referee for his/her helpful comments and suggestions.

\section{Conflicts of Interest}

The authors declare no conflicts of interest regarding the publication of this paper.

\section{References}

[1] World Health Organization (WHO) (2019) Raised Blood Pressure. https://www.who.int/gho/ncd/risk_factors/blood_pressure_prevalence_text/en/

[2] WHO and International Society of Hypertension Writing Group (2003) 2003 World Health Organization (WHO)/International Society of Hypertension (ISH) Statement on Management of Hypertension. Journal of Hypertension, 11, 1983-1992. https://doi.org/10.1097/00004872-200311000-00002

[3] Gaziano, T.A., Bitton, A., Anand, S. and Weinstein, M. (2009) The Global Cost of Nonoptimal Blood Pressure. Journal of Hypertension, 27, 1472-1477. https://doi.org/10.1097/HJH.0b013e32832a9ba3

[4] Benjamin, E.J., Blaha, M.J., Chiuve, S.E., et al. (2017) Heart Disease and Stroke Statistics-2017 Updates: A Report from the American Heart Association. Circulation, 135, e146-e603. https://doi.org/10.1161/CIR.0000000000000491

[5] Wang, G., Grosse, G.S.D. and Schooley, M.W. (2017) Conducting Research on the Economics of Hypertension to Improve Cardiovascular Health. American Journal of Preventive Medicine, 53, S115-S117. https://doi.org/10.1016/j.amepre.2017.08.005

[6] Centers for Disease Control and Prevention (2016) High Blood Pressure Fact Sheet. https://www.cdc.gov/dhdsp/data_statistics/fact_sheets/fs_bloodpressure.htm

[7] Ministry of Health, Welfare, and Labor (2018) Heisei 28 nendo kokumin iryouhi no gayou (Summary of National Medical Expenditures, Fiscal Year 2016) (in Japanese).

[8] Blanchflower, D.G. and Oswald, A.J. (2008) Hypertension and Happiness across Nations. Journal of Health Economics, 27, 218-233. https://doi.org/10.1016/j.jhealeco.2007.06.002

[9] Mojon-Azzi, S. and Sousa-Pazo, A. (2011) Hypertension and Life Satisfaction: An Analysis Using Data from the Survey of Health, Aging and Retirement in Europe. Applied Economics Letters, 18, 183-187. https://doi.org/10.1080/13504850903508291

[10] Japanese Society of Hypertension (2014) Guidelines for the Management of Hypertension 2014. (In Japanese) http://www.jpnsh.jp/data/jsh2014/jsh2014v1_1.pdf

[11] Blood Pressure Association (2008) Blood Pressure Chart for Adults. http://www.bloodpressureuk.org/BloodPressureandyou/Thebasics/Bloodpressurech $\underline{\operatorname{art}}$

[12] National Heart, Lung and Blood Institute, US Department of Health \& Human Services (2015) Description of High Blood Pressure. https://www.nhlbi.nih.gov/ 
[13] Guidelines Subcommittee (1999) 1999 World Health Organization-International Society of Hypertension Guidelines for Management of Hypertension. Journal of Hypertension, 17, 151-183. https://doi.org/10.1097/00004872-199917020-00001

[14] Whelton, P.K., Carey, R.M., Arrow, W.S., et al. (2018) 2017 ACC/AHA/AAPA/ ABC/ACPM/AGS/APhA/ASH/ASPC/NMA/PCNA Guideline for the Prevention, Detection, Evaluation, and Management of High Blood Pressure in Adults: A Report of the American College of Cardiology/American Heart Association Task Force on Clinical Practice Guidelines. Hypertension, 71, e13-e115.

https://doi.org/10.1161/HYP.0000000000000076

[15] Whelton, P.K., Carey, R.M., Arrow, W.S., et al. (2018) 2017 Guideline for Blood Pressure in Adults. American College of Cardiology.

http://www.acc.org/latest-in-cardiology/ten-points-to-remember/2017/11/09/11/41/ 2017-guideline-for-high-blood-pressure-in-adults

[16] Carey, R.M. and Whelton, P.K. (2018) Prevention, Detection, Evaluation, and Management of High Blood Pressure in Adults: Synopsis of the 2017 American College of Cardiology/American Heart Association Hypertension Guideline. Annals of Internal Medicine, 168, 351-335. https://doi.org/10.7326/M17-3203

[17] Levine, G.N., O'Gara, P.T., Beckman, J.A., et al. (2019) Modifications, and Evolution of ACC/AHA Clinical Practice Guidelines: An Update for Our Constituencies. Journal of the American College of Cardiology, 73, 1990-1998. https://doi.org/10.1016/j.jacc.2019.02.012

[18] Chobanian, A.V., Bakris, G.L., Black, H.B., et al. (2003) Seventh Report of the Joint National Committee on Prevention, Detection, Evaluation, and Treatment of High Blood Pressure. Hypertension, 42, 1206-1252. https://doi.org/10.1161/01.HYP.0000107251.49515.c2

[19] National Heart, Lung, and Blood Institute, U.S. Department of Health and Human Services (2004) National High Blood Pressure Education Program: Seventh Report of the Joint National Committee on Prevention, Detection, Evaluation, and Treatment of High Blood Pressure (Complete Report).

https://www.nhlbi.nih.gov/files/docs/guidelines/jnc7full.pdf

[20] Khera, R., et al. (2018) Impact of 2017 ACC/AHA Guidelines on Prevalence of Hypertension and Eligibility for Antihypertensive Treatment in United States and China: Nationally Representative Cross Sectional Study. The British Medical Journal, 362, k2357. https://doi.org/10.1136/bmj.k2357

[21] Chuang, S.Y., Chang, H.Y., Cheng, H.M., Pan, W.-H. and Chen, C.-H. (2019) Impacts of the New 2017 ACC/AHA Hypertension Guideline on the Prevalence of Brachial Hypertension and Its Concordance with Central Hypertension. American Journal of Hypertension, 32, 409-417. https://doi.org/10.1093/ajh/hpz008

[22] Marchesan, L.B. and Spritzer, P.M. (2019) ACC/AHA 2017 Definition of High Blood Pressure: Implications for Women with Polycystic Ovary Syndrome. Fertility and Sterility, 111, 579-587. https://doi.org/10.1016/j.fertnstert.2018.11.034

[23] Williams, B., Mancia, G., Spiering, W., et al. (2018) 2018 ESC/ESH Guidelines for the Management of Arterial Hypertension. European Heart Journal, 39, 3021-3104.

[24] Nerenberg, K.A., Zarnke, K.B., Leung, A.A., et al. (2018) Hypertension Canada's 2018 Guidelines for Diagnosis, Risk Assessment, Prevention, and Treatment of Hypertension in Adults and Children. Canadian Journal of Cardiology, 34, 506-525.

[25] Goupil, R., Lamarre-Cliche, M. and Vallée, M. (2018) The 2017 American College of Cardiology/American Heart Association vs Hypertension Canada High Blood Pressure Guidelines and Potential Implications. Canadian Journal of Cardiology, 
34, 665-669. https://doi.org/10.1016/j.cjca.2018.01.011

[26] American Diabetes Association (2018) Cardiovascular Disease and Risk Management: Standards of Medical Care in Diabetes-2018. Diabetes Care, 41, S86-S104. https://doi.org/10.2337/dc18-S009

[27] Hirawa, N., Umemura, S. and Ito, S. (2019) Viewpoint on Guidelines for Treatment of Hypertension in Japan. Circulation Research, 124, 981-983. https://doi.org/10.1161/CIRCRESAHA.119.314991

[28] American Academy of Family Physicians (AAFP) (2017) AAFP Decides to Not Endorse AHA/ACC Hypertension Guideline, Academy Continues to Endorse JNC8 Guideline. AAFP News.

https://www.aafp.org/news/health-of-the-public/20171212notendorseaha-accgdlne. $\underline{\mathrm{html}}$

[29] Wright, J.T., Williamson, J.D., Whelton, P.K., et al. (2015) A Randomized Trial of Intensive versus Standard Blood-Pressure Control. The New England Journal of Medicine, 373, 2103-2116. https://doi.org/10.1056/NEJMoa1511939

[30] Boston University and the National Heart, Lung, \& Blood Institute (2019) Framingham Heart Study. https://www.framinghamheartstudy.org/

[31] Harvard Health Publishing (2017) The Power of the Placebo Effect. Harvard Medical School. https://www.health.harvard.edu/mental-health/the-power-of-the-placebo-effect

[32] Hoenemeyer, T.W., Kaptchuk, T.J., Mehta, T.S. and Fontaine, K.R. (2018) Open-Label Placebo Treatment for Cancer-Related Fatigue: A Randomized-Controlled Clinical Trial. Scientific Reports, 8, Article No. 2784. https://doi.org/10.1038/s41598-018-20993-y

[33] Leung, A.A., Chang, H.J., McAlister, F.A., et al. (2018) Applicability of the Systolic Blood Pressure Intervention Trial (SPRINT) to the Canadian Population. Canadian Journal of Cardiology, 34, 670-675. https://doi.org/10.1016/j.cjca.2018.01.008

[34] ACCORD Study Group (2010) Effect of Intensive Blood-Pressure Control in Type 2 Diabetes Mellitus. The New England Journal of Medicine, 362, 1575-1585. https://doi.org/10.1056/NEJMoa1001286

[35] Prospective Studies Collaboration (2002) Age-Specific Relevance of Usual Blood Pressure to Vascular Mortality: A Meta-analysis of Individual Data for One Million Adults in 61 Prospective Studies. The Lancet, 360, 1903-1913. https://doi.org/10.1016/S0140-6736(02)11911-8

[36] Ettehad, D., Emdin, C.A., et al. (2016) Blood Pressure Lowering for Prevention of Cardiovascular Disease and Death: A Systematic Review and Meta-Analysis. The Lancet, 387, 957-967. https://doi.org/10.1016/S0140-6736(15)01225-8

[37] Joffres, M.R., Mamet, P., MacLean, D.R., L'italien, G.J. and Fodor, G. (2001) Distribution of Blood Pressure and Hypertension in Canada and the United States. American. Journal of Hypertension, 14, 1099-1105. https://doi.org/10.1016/S0895-7061(01)02211-7

[38] Rapsomaniki, E., Timmis, A., George, J., et al. (2014) Blood Pressure and Incidence of Twelve Cardiovascular Diseases: Lifetime Risks, Healthy Life-Years Lost, and Age-Specific Associations in 1.25 Million People. The Lancet, 383, 1899-1911. https://doi.org/10.1016/S0140-6736(14)60685-1

[39] Muntner, P., Carey, R.M., Gidding, S., et al. (2018) Potential U.S. Population Impact of the 2017 ACC/AHA High Blood Pressure Guideline. Journal of the American College of Cardiology, 71, 109-118. https://doi.org/10.1016/j.jacc.2017.10.073 
[40] Ihm, S.H., Bakris, G., Sakuma, I., et al. (2019) Controversies in the 2017 ACC/AHA Hypertension Guidelines: Who Can Be Eligible for Treatments under the New Guidelines?-An Asian Perspective. Circulation Journal, 83, 504-510.

[41] Department of Public Health, Shiga University of Medical Science (2018) NIPPON DATA 2010. (In Japanese) https://hs-web.shiga-med.ac.jp/Nippondata/NIPPONDATA2010/

[42] Miura, K., Nagai, M. and Ohkubo, T. (2013) Epidemiology of Hypertension in Japan-Where Are We Now? Circulation Journal, 77, 2226-2231.

[43] Fujiyoshi, A., Ohkubo, T., Miura, K., et al. (2012) Blood Pressure Categories and Log-Term Risk of Cardiovascular Disease According to Age Group in Japanese Men and Women. Hypertension Research, 35, 947-953.

https://www.nature.com/articles/hr201287

https://doi.org/10.1038/hr.2012.87

[44] Asayama, K., Satoh, M., Murakami, Y., et al. (2014) Cardiovascular Risk With and Without Antihypertensive Drug Treatment in the Japanese General Population Participant-Level Meta-Analysis. Hypertension, 63, 1189-1197. https://doi.org/10.1161/HYPERTENSIONAHA.113.03206

[45] Department of Epidemiology and Public Health, Department of Epidemiology and Public Health, Graduate School of Medical Sciences, Kyushu University (2018) Kugayama Kenkyu (Kugayama Study). (In Japanese) http://www.hisayama.med.kyushu-u.ac.jp/about/index.html

[46] Honda, T., Yoshida, D., Hata, J., et al. (2018) Development and Validation of Modified Risk Prediction Models for Cardiovascular Disease and Its Subtypes: The Hisayama Study. Atherosclerosis, 279, 38-44. https://doi.org/10.1016/j.atherosclerosis.2018.10.014

[47] Nawata, K., Sekizawa, Y. and Kimura, M. (2018) Evaluation of Blood Pressure Control Medicines Using Health and Medical Checkup Data in Japan: Alternative Methods for Randomized Controlled Trials. Health, 10, 587-603. https://doi.org/10.4236/health.2018.105047

[48] Nawata, K., Matsumoto, A., Kajihara, K. and Kimura, M. (2017) Evaluation of the Distribution of and Factors Affecting Blood Pressure Using Medical Checkup Data in Japan. Health, 9, 124-137. https://doi.org/10.4236/health.2017.91009

[49] Nawata, K. and Kimura, M. (2018) Empirical Studies of Effects of High Blood Pressure on Medical Costs and Heart Disease: Is the 2017 ACC/AHA Guideline Supported by Enough Evidence? Health, 10, 1498-1519. https://doi.org/10.4236/health.2018.1011115

[50] Nawata, K. and Kimura, M. (2018) Does High Systolic Blood Pressure Truly Increase Medical Expenditure? An Empirical Analysis of the New 2017 ACC/AHA Hypertension Guideline. Health, 10, 1044-1065. https://doi.org/10.4236/health.2018.108079

[51] Japanese Law Translation (2009) Industrial Safety and Health Act. http://www.japaneselawtranslation.go.jp/law/detail/?id=1926\&vm=\&re

[52] Ministry of Health Labour and Welfare (2016) Diseases of the Circulatory System. https://www.mhlw.go.jp/toukei/sippei/dl/naiyou09.pdf

[53] World Health Organization (2019) ICD-10 Online Versions. https://www.who.int/classifications/icd/icdonlineversions/en/

[54] Cox, D.R. (1972) Regression Models and Life-Tables. Journal of the Royal Statistical Society: Series B (Methodological), 34, 187-202. 
https://doi.org/10.1111/j.2517-6161.1972.tb00899.x

[55] American Heart Association (AHA) (2017) About Cholesterol. http://www.heart.org/HEARTORG/Conditions/Cholesterol/AboutCholesterol/Abo ut-Cholesterol_UCM_001220_Article.jsp\#.Wtrw2ojFKUk

[56] WHO (2018) Raised Cholesterol. http://www.who.int/gho/ncd/risk_factors/cholesterol_text/en/

[57] Centers for Disease Control and Prevention (2017) LDL and HDL Cholesterol: "Bad" and "Good" Cholesterol. https://www.cdc.gov/cholesterol/ldl_hdl.htm

[58] American Heart Association (2017) HDL (Good), LDL (Bad) Cholesterol and Triglycerides.

https://www.heart.org/en/health-topics/cholesterol/hdl-good-ldl-bad-cholesterol-an d-triglycerides

[59] U.S. National Library of Medicine (2018) Medical Encyclopedia. https://medlineplus.gov/encyclopedia.html

[60] Medline Plus (2018) High Blood Pressure Medicines. U.S. National Library of Medicine https://medlineplus.gov/ency/article/007484.htm

[61] The Japanese Society of Hypertension (2014) Guidelines for the Management of Hypertension 2014. (In Japanese) http://www.jpnsh.jp/data/jsh2014/jsh2014v1_1.pdf

[62] Laurent, S. (2017) Antihypertensive Drugs. Pharmacological Research, 124, 116-125. https://doi.org/10.1016/j.phrs.2017.07.026

[63] WebMed (2018) Side Effects of High Blood Pressure Medications. https://www.webmd.com/hypertension-high-blood-pressure/guide/side-effects-hig h-blood-pressure-medications\#1

[64] Kario, K., Thijs, L. and Staessen, J.A. (2019) Blood Pressure Measurement and Treatment Decisions, Masked and White-Coat Hypertension. Circulation Research, 124, 990-1008. https://doi.org/10.1161/CIRCRESAHA.118.313219

[65] Harvard Heath Publishing (2017) Controlling Blood Pressure with Fewer Side Effects. Harvard Medical School.

https://www.health.harvard.edu/heart-health/controlling-blood-pressure-with-fewe r-side-effects 


\section{Appendix A: Cox Proportional Hazard Method When Time-Dependent or Time-Varying Covariates Are Included}

In studies such as SPRINT, the Cox proportional hazard model was used. However, when the covariates include time-dependent or time-varying covariates that change over time, it is necessary to consider their influence. To the best of our knowledge, this section is the first explicit representation of medical data analyses. Suppose that there are $n$ individuals, $i=1,2, \cdots, n$, and the time continuous. Let $t_{i}$ be the time that $i$ begins to undergo HD treatment. Since the continuous time model is considered, $t_{i} \neq t_{j}, i \neq j$. Let $t_{1}<t_{2}<\cdots<t_{n}$. In the Cox proportional hazard model, the hazard function $h_{i}(t)$ is given by a part that depends on time and a part that only depends on the characteristics of the individual, represented by a vector of covariates, $x_{i}$, that is unchanged over time. Under these conditions, we get

$$
h_{i}(t)=\lambda(t) \exp \left(x_{i}^{\prime} \beta\right) .
$$

For the estimation of the model, the partial likelihood method (also known as Cox regression) is used. Let $A_{i}$ be a set of individuals who do not undergo HD treatment. The $i$-th individual begins to undergo HD treatment at $t_{i}$. (Individual $i$ begins to undergo HD treatment just after $t_{i}$ and $i \in A_{i}$.) From time $t$ to $t+\Delta t$, where $\Delta t$ is an infinitesimal time interval, the probability of one individual beings to undergo $\mathrm{HD}$ treatment is approximately given by $\sum h_{j}(t) \Delta t$. The conditional probability that $i$ undergoes HD treatment is given by ${ }^{j \in A_{i}}$

$$
L_{i}=h_{i}\left(t_{i}\right) \Delta t / \sum_{j \in A_{i}} h_{j}(t) \Delta t=\exp \left(x_{i}^{\prime} \beta\right) / \sum_{j \in A_{i}} \exp \left(x_{j}^{\prime} \beta\right) .
$$

By multiplying the conditional probabilities for all individuals, we get the partial likelihood, which is similar to the logit method,

$$
L=L_{1} \cdot L_{2} \cdots L_{n} .
$$

By maximizing this function, we can obtain estimators. In this estimation method, only orders of $t_{i}$ are used, and values of $t_{i}$ themselves are not used. However, the Cox method assumes that the hazard function is given by the product of the time-dependent and non-time-dependent parts. However, when the values of covariates change over time, this creates a serious problem. Health conditions change very rapidly over time, and we cannot use the Cox method in these cases.

Therefore, we should use a model as shown in the following example. Let time $t$ be a discrete variable, and the value of the variable changes periodically (for example, by year or month), and the value of variable does not change within a period. Let $y_{i t}^{*}$ be a latent variable representing the health conditions of the individual $i$ at time $t$. $y_{i t}^{*}$ is given by the linear function of a vector $x_{i t}$ that represents various characteristics of $i$ and is given by

$$
y_{i t}^{*}=x_{i t}^{\prime} \beta+u_{i t}, \quad i=1,2, \cdots, n
$$

$x_{i t}$ may depend on $t$, Individual $i$ does not undergo HD treatment if $y_{i t}^{*} \geq 0$ 
and receives HD treatment if $y_{i t}^{*}<0$. Let $G(u)$ be a distribution function of $u_{i t}$. Then the probabilities of undergoing and not undergoing HD treatment at time $t$ are:

$$
P\left[u_{i t} \geq-x_{i t}^{\prime} \beta\right]=1-G\left(-x_{i t}^{\prime} \beta\right) \text { and } P\left[u_{i t}<-x_{i t}^{\prime} \beta\right]=G\left(-x_{i t}^{\prime} \beta\right)
$$

In this paper, we used probit models in each period. To clarify the problems in the Cox proportional hazard model, we assume the exponential distribution $G(u)=1-\exp (-u), u \geq 0$ as $G(u)$. We get

$$
P\left[u_{i t} \geq-x_{i t}^{\prime} \beta\right]=\exp \left(x_{i t}^{\prime} \beta\right), \quad P\left[u_{i t}<x_{i t}^{\prime} \beta\right]=1-\exp \left(x_{i t}^{\prime} \beta\right) .
$$

We let $t_{i}$ be the sample period of individual $i$. If $i$ does not undergo HD treatment until $t_{i}-1$ and undergoes $\mathrm{HD}$ treatment at $t_{i}$, the probability is given by

$$
P_{1 i}=\left\{\prod_{t=1}^{t_{i}-1} \exp \left(x_{i t}^{\prime} \beta\right)\right\}\left\{1-\exp \left(x_{i t}^{\prime} \beta\right)\right\}=\exp \left\{\sum_{t=1}^{t_{i}-1} x_{i t}^{\prime} \beta\right\}\left\{1-\exp \left(x_{i t}^{\prime} \beta\right)\right\} .
$$

If $i$ does not undergo HD treatment during the sample period, the probability becomes

$$
P_{0 i}=\prod_{t=1}^{t_{i}} \exp \left(x_{i t}^{\prime} \beta\right)=\exp \left(\sum_{t=1}^{t_{i}} x_{i t}^{\prime} \beta\right)
$$

Let $y_{i}=1$ if $i$ undergoes HD treatment and $y_{i}=0$ if $i$ does not undergo HD treatment, and then we get the likelihood function,

$$
L=\prod_{y_{i}=1} P_{1 i} \prod_{y_{i}=0} P_{0 i} \text {. }
$$

Accordingly, the log of likelihood becomes

$$
\begin{aligned}
\log L & =\sum_{i=1}^{n}\left[\sum_{t=1}^{t_{i}-1} x_{i t}^{\prime} \beta+y_{i} \log \left\{1-\exp \left(x_{i t_{i}}^{\prime} \beta\right)\right\}+\left(1-y_{i}\right) x_{i_{i}}^{\prime} \beta\right] \\
& =\sum_{i=1}^{n}\left[\left(t_{i}-1\right)\left(\bar{x}_{i}^{\prime} \beta\right)+y_{i} \log \left\{1-\exp \left(x_{i t_{i}}^{\prime} \beta\right)\right\}+\left(1-y_{i}\right) x_{i_{i}}^{\prime} \beta\right], \\
\bar{x}_{i}= & \frac{1}{t_{i}-1} \sum_{t=1}^{t_{i}-1} x_{i t}
\end{aligned}
$$

This means that we cannot use a simple Cox proportional hazard method when there exist time-dependent or time-varying variables that fluctuate rapidly over time.

\section{Appendix B: Effect of Antihypertensive Drugs on DBP}

The results of the estimation of the model evaluating the effects of antihypertensive drugs on DBP are given in Table 6, where Anamnesis is a dummy variable (1: with anamnesis; 0: otherwise) and Trend represents the time trend. For details, see Model 3 of Nawata, Sakizawa, and Kimura [47]. 